\title{
ENCUENTROS PSICO-AFECTIVOS: ESTRATEGIA LÚDICA Y CREATIVA EN FAVOR DE UNA EXPERIENCIA ESCOLAR INTEGRAL ${ }^{1}$
}

\section{Psycho-Affective Encounters: Playful and Creative Strategy for an Inclusive School Experience}

\author{
Patricia Liranzo Soto ${ }^{2}$, Rocío Hernández Mella ${ }^{3}$, \\ Andreína Jiménez Soto ${ }^{4}$ y Berenice Pacheco Salazar ${ }^{5}$
}

Recibido: 18/2/2017 • Aprobado: 20/5/2017

\section{Resumen}

El artículo "Encuentros Psico-Afectivos: estrategia lúdica y creativa en favor de una experiencia escolar integral" describe lo acontecido en los talleres organizados para producir una práctica, por medio del juego y el arte, alrededor del tema "cuerpo" en estudiantes de primaria. El estudio corresponde a la intervención ejecutada dentro del marco de la investigación "Arte y afectividad: desarrollo de actitudes positivas y de una expresividad creativa en una experiencia escolar inclusiva”, cuyo propósito implicó la descripción de la vivencia educativa de niños y niñas de $1^{\circ}$ a $4^{\circ}$ grados en interacción con sus docentes para producir una estrategia lúdica y creativa que aportara al desarrollo de las potencialidades de todos los actores involucrados. Igualmente, analiza las manifestaciones producidas en un promedio de 320 estudiantes del primer ciclo del Nivel Básico en cuatro escuelas del sector público del municipio de Yamasá, República Dominicana. Los Encuentros Psico-Afectivos (EPA) se estructuraron con un nivel de complejidad creciente en el uso del cuerpo. Los ejercicios y dinámicas desarrollados en los talleres EPA mostraron tener un efecto positivo en la expresión de sentimientos y manifestaciones creativas de los estudiantes participantes, lo que permite concluir que, por medio del arte, es posible canalizar las conductas disruptivas abriendo espacios para una experiencia educativa integral e inclusiva.

Palabras clave: experiencia educativa; psicología educativa; expresión artística; dinámicas de grupo.

1. Esta es la quinta entrega publicada en Ciencia y Sociedad de los resultados de este proyecto de investigación..

2. Instituto Tecnológico de Santo Domingo (INTEC), República Dominicana. Correo electrónico: patricia.liranzo@intec.

3. Profesora del Instituto Tecnológico de Santo Domingo (INTEC), República Dominicana.

\section{Abstract}

The article "Psycho-Affective Encounters: Playful and Creative Strategy for an Inclusive School Experience" describes what happened in organized workshops to produce a practice through game and art around the subject of The Body in elementary students and at the same time which will be motivating for their teachers. The study corresponds to the intervention carried out within the framework of the research "Art and Affectivity: development of positive attitudes and creative expressivity in an inclusive school experience" whose purpose implied the description of the educational involvement of children from first to fourth grade in interaction with their teachers for the establishment of a playful and creative strategy that would contribute to the development of the potentialities of all participants involved. It also analyzes the manifestations produced in an average of 320 students of the first cycle of the basic level from four public schools in the municipality of Yamasá, Dominican Republic. The Psycho- Affective Encounters (EPA, in spanish) were executed with an increasing level of complexity in the use of the body through: workshop 1. "Experiential Body", workshop 2. "Expressing Body", and workshop 3. "Communicative Body". The exercises and dynamics developed in the EPA workshops showed a positive effect on the expression of feelings and creative manifestations of the students who participated. This leads to the conclusion that through art it is possible to channel disruptive behaviors by opening spaces for an integral and inclusive educational experience.

Keywords: educational experience; educational psychology; art expression; group dynamics.

4. Profesora del Instituto Tecnológico de Santo Domingo (INTEC), República Dominicana.

5. Profesora del Instituto Tecnológico de Santo Domingo (INTEC), República Dominicana. 


\section{Introducción}

El artículo "Encuentros Psico-Afectivos: estrategia lúdica y creativa en favor de una experiencia escolar integral" resulta ser el último de una serie de cinco trabajos emanados de la investigación "Arte y afectividad: desarrollo de actitudes positivas y de una expresividad creativa en una experiencia escolar inclusiva", la cual se desarrolló con el fin de conocer la exposición particular y única de las potencialidades personales del estudiantado de nivel primario, así como su manifestación afectiva, en el proceso de aprendizaje ocurrido en interacción con los docentes.

El articulo refiere, la descripción y análisis de una experiencia lúdica y creativa efectuada con el estudiantado participante en la investigación "Arte y afectividad", 123 niños y niñas de $1^{\circ}$ a $4^{\circ}$ grados del Nivel Básico, pertenecientes a cuatro centros educativos localizados en el municipio de Yamasá, del Distrito Educativo 17-01, en la Regional Educativa de Monte Plata, ubicada en la zona Este de la República Dominicana.

La acción desarrollada en los EPA (Encuentros Psicoafectivos) a través de sus talleres, tuvo la intención de facilitar la construcción de una estrategia que invoca el juego y el arte y, una vez que sea incorporada a la didáctica de la clase, permitirá la expresión y desarrollo de las capacidades de todos los actores involucrados y logrará una vivencia escolar motivadora, inclusiva, creativa y significativa.

El propósito detrás de la práctica ejecutada en los EPA consiste en que todo el personal que conforma la escuela, estudiantes, docentes, especialistas en orientación y psicología, directivos y asistentes, se involucren en actividades artísticas como parte de las acciones comunes del centro educativo y desarrollen técnicas creativas a través de las cuales enriquecer la metodología de enseñanza de todas las asignaturas.
El impacto -a veces inmediato- en la salud emocional, afectiva y física que tiene el arte en los niños, niñas, adolescentes y adultos lleva a propugnar, junto a lo postulado por Jiménez (2010), una educación a través del arte, como vía idónea del desarrollo de capacidades, valores, y formación de ciudadanía.

Siguiendo a Abad (2009), la educación a través del arte representa un puente que conecta las diferentes realidades que las personas comparten, y no únicamente una manifestación particular del espíritu humano. El arte como ejercicio educativo logra poner la cultura a disposición de todos y hacer posible que cada uno pueda construirla. Esta es una función socializadora del arte que lo sitúa más allá de lo estético y representa un pilar para conseguir los cambios que amerita una sociedad que persigue ser democrática.

Una formación integral incluye la educación artística y la educación a través del arte como ejes clave para lograr la equidad de oportunidades. El arte constituye un instrumento ideal para reinventar la función docente, evitando que se produzca un trabajo pedagógico un tanto mecánico y motivando a que se realice una labor educativa contextualizada (según las características personales, sociales y culturales de cada grupo de estudiantes) y sensible, referida a las actitudes e intereses de los educandos.

Postulados de la autora Pozzoli (2007) permiten sostener que el arte también tiene un poder reconstructor, al constituirse en una vía de expresión y posibilitar el reconocimiento de lo que acontece en la interioridad de la persona. Resulta sanador el poder expresar lo profundo con algún recurso simbólico de los que el arte acostumbra a hacer uso.

El arte abre las vías de comunicación al interno de un colectivo humano, tal y como viene a ser la experiencia educativa en el aula de clase, propiciando las expresiones tanto verbales como no 
verbales de los individuos. Ahora bien, es posible constatar que para muchos adultos y jóvenes e incluso niños el arte no forma parte de sus vidas, lo que lleva a Badilla (2011) a postular que, tal parece, que a las personas se les olvida cómo practicar el arte. De ahí la importancia de que los Encuentros Psico-Afectivos formen parte de la vida en la escuela.

Los Encuentros Psico-Afectivos integran un conjunto de cuatro talleres alrededor del tema "cuerpo". El primer taller corresponde a "Cuerpo Vivencial", el segundo taller a "Cuerpo que Expresa", el tercer taller a "Cuerpo que Comunica" y el cuarto taller a "Cuerpo que Representa". El cuerpo nos conforma y, a través de él, conocemos y creamos (Piaget, 1986). Esto revela la relevancia de alcanzar al cuerpo con el arte, de que se sienta tocado de manera real y simbólica, y esto es tanto más importante, mientras más jóvenes sean las personas involucradas en el taller.

Asimismo, el estado emocional tiene su asiento en el cuerpo y este cuerpo representa la puerta de entrada al proceso mismo de reflexión y conformación del mundo emocional de una persona. Reconocer lo emocional significa encontrarse con uno mismo abriendo la posibilidad de una total aceptación, tal y como lo expresa Maturana (1990; 1992).

La escuela es un entorno donde la afectividad se expresa a través de las relaciones sociales, sin embargo, el desarrollo de estas últimas amerita ser restablecido, de modo que alimenten verdaderamente el sentir y el conocer de las personas. Sin embargo, de acuerdo a explicaciones de De Zubiria (en Villegas, 2010), cada vez es más difícil que los niños, las niñas y adolescentes sean capaces de expresarse emocionalmente, con lo que la importancia de los EPA se acrecienta.
La dimensión afectiva debe hacerse relevante en el espacio educativo y organizacional de la escuela. En el aula significa rescatar y cimentar el aprendizaje de la afectividad sobre la experiencia cotidiana de las personas, en sus intercambios particulares y sociales, mientras se produce el proceso aprendizaje-enseńanza cognoscitivo. Y una vía expedita para lograr este propósito se tiene en las diversas manifestaciones artísticas.

Las actividades que conformaron cada taller EPA resultaron ser una oportunidad que tuvieron los nińos y nińas participantes en este estudio de expresar su capacidad creativa, a la vez que se manifestaba su afectividad, tanto individual como en grupo.

\section{Objetivos}

Objetivo general: desarrollar actitudes positivas y una expresividad creativa como herramientas para la construcción de una experiencia escolar inclusiva.

Objetivo específico: propiciar en el estudiantado, a través de una serie de talleres artísticos, el reconocimiento y valoración de su propio cuerpo como vía de expresión de la imaginación, las vivencias y las emociones, favorecedoras de una experiencia escolar significativa e inclusiva.

\section{Beneficiarios directos}

Los beneficiarios directos fueron 300 estudiantes del primer ciclo del Nivel Básico, 20 docentes del primer ciclo del Nivel Básico y cuatro centros del Distrito Educativo 17-01 de Yamasá. 
Tabla 1. Estudiantes y docentes participantes en talleres EPA por centro educativo

\begin{tabular}{lcccccc}
\hline Encuentros Psico-Afectivos & CH & RC & FPC & MM & Tot. Centros (4) & Docentes \\
\hline Taller 1. "Cuerpo vivencial" & 173 & 78 & 68 & 79 & 398 & $14^{*}$ \\
Taller 2. "Cuerpo que expresa" & 172 & 59 & 58 & 68 & 357 & 2 \\
Taller 3. "Cuerpo que comunica" & 53 & 59 & 62 & 33 & 207 & 0 \\
\hline
\end{tabular}

*Tres docentes no se encuentran registradas en la lista de participantes, pero sí en el diario de campo de una de las facilitadoras.

\section{Procedimiento}

Los cuatro talleres EPA fueron programados para ejecutarse en los meses de septiembre y octubre del año escolar 2014-2015. En ese sentido, se logró desarrollar sin inconvenientes los dos primeros talleres, el tercer encuentro se realizó en fechas modificadas, respecto a lo planificado, mientras el cuarto taller no se ejecutó debido a las huelgas reiteradas convocadas en Yamasá por sectores de la sociedad civil en demanda de la satisfacción de necesidades de la comunidad. Estas huelgas o manifestaciones impidieron la entrada y salida de personas fuera de las inmediaciones del municipio.

Los talleres fueron realizados en cada una de las cuatro escuelas seleccionadas: $\mathrm{CH}, \mathrm{RC}, \mathrm{FPC}$ y MM. Hay que seńalar que, del número esperado de docentes programado para que recibieran los talleres junto a su grupo de estudiantes, catorce (14) participaron de manera activa en el primer taller, "Cuerpo Vivencial". Para el segundo taller, la cantidad se redujo drásticamente a dos (2) docentes y, en el tercer taller, ninguna maestra participó de manera activa, si bien algunas estuvieron físicamente presentes en las actividades que conformaban los talleres.

Con respecto al estudiantado, en el primer taller se sobrepasó con creces la meta estimada de 300 participantes, puesto que asistieron 398 niños y nińas de $1^{\circ}$ a $4^{\circ}$ grados del Nivel Básico. Esto representa el $32 \%$ por encima del $100 \%$ esperado. Para el segundo taller, fueron 357 participantes en total, cantidad que muestra un aumento del 19\% por encima del $100 \%$ de estudiantes esperado. Al tercer taller asistieron 207 participantes, por lo que esta cantidad evidencia una disminución notable en la implicación de los niños y niñas, sobre todo en las escuelas $\mathrm{CH}, \mathrm{MM}$ y FPC.

La disminución de la asistencia al tercer taller se explica debido a la movilidad de estudiantes de una escuela a otra, así como las continuas inasistencias de los mismos. A su vez, el equipo de facilitadores de los talleres se vio afectado por el cambio de fecha en el cronograma, a partir del acontecimiento de las huelgas, ya que se trataba de estudiantes universitarios con compromisos de su formación académica.

La participación activa de estudiantes del primer ciclo de Nivel Básico, de $1^{\circ}$ a $4^{\circ}$ grados, en los tres talleres ejecutados, alcanzó un promedio de 320 niños y niñas, con lo cual se puede afirmar que se sobrepasó la cantidad esperada de estudiantes participantes al ciclo de talleres.

\section{Resultados}

\section{Taller 1. "Cuerpo Vivencial"}

Objetivo: reconocer y desarrollar el esquema corporal, entendido como la imagen del cuerpo y su conocimiento inmediato, tanto en estado de reposo como en movimiento.

En primer lugar, y con respecto al objetivo planteado, los niños y las nińas participantes del taller fueron capaces de reconocer su esquema corporal 
global, así como cada parte del mismo, tanto en actividad como en reposo.

A partir del análisis realizado al taller, se establecen cuatro grandes categorías: comportamiento, casos excepcionales, sentimientos vivenciados y valoración de los nińos y niñas participantes.

Categoria I. Comportamiento. De lo observado y registrado durante la ejecución de este primer taller en las cuatro escuelas, y considerando algunas variaciones entre las mismas, el comportamiento se refiere al nivel de participación, receptividad, cooperación, rango de atención, conductas disruptivas y conductas de agresión.

Los niños de menor edad, los de primer y segundo grados, fueron quienes disfrutaron más y ejecutaron mejor los ejercicios de este primer taller, que en cierta medida resultó un tanto simple para los niños y niñas mayores, de tercer y cuarto grados, incluyendo, como parte de este razonamiento, la sobreedad existente en estos grados.

Con respecto a la participación, hubo que hacer esfuerzos sostenidos para motivar a todo el grupo a intervenir en las actividades. En general, se contaba con un núcleo de trabajo de la mitad de los participantes que sí mostraba entusiasmo en la ejecución de los ejercicios, mientras el resto utilizaba el espacio del taller para todo tipo de acciones enérgicas, entre las que se encontraban corretear, salir al patio, gritar, arrebatar objetos a otros compañeros, y jugar de manera agresiva; y un grupo reducido mostraba poco interés a involucrarse en las actividades. Esto produjo que la cooperación fuese leve, lo que afectó la cohesión.

Del grupo que participaba activamente, se logró un rango de atención moderado, ya que le costaba sostener una actividad por mucho tiempo. Esto provocó cambio e inclusión de actividades, a partir de improvisar dinámicas entre las planificadas.

Un elemento a destacar fue la manifestación de conductas disruptivas y de agresión que para nosotros, observadores externos, resultaron significativas, mientras que parecían comportamientos comunes dentro del modo de relacionarse de los niños y las niñas entre sí, y frente a la maestra. Es decir, expresiones de la cotidianidad, un hábito más que integrado y convencional. Las conductas agresivas observadas fueron: dar empujones y puñetazos, recoger piedras en el patio para lanzarlas al compañero fuente de la agresión, expresar insultos verbales y malas palabras, indistintamente entre niñas y niños.

Categoría II. Casos excepcionales. Esta categoría implica algunas experiencias particulares de niños $\mathrm{y}$ nińas, quienes mostraron una actitud y participación distintas en los talleres. Este es el caso de $(\mathrm{Y})$, niño de ascendencia haitiana (indicado por la discriminación observada de otros niños hacia él), quien durante la observación no-participante de su experiencia escolar, al inicio de la investigación, se mostraba pasivo, no responsivo, y parecía no comprender las instrucciones. Durante el taller, sin embargo, se mostró, no solamente dispuesto y colaborador, sino muy feliz de ser parte del taller, como si esta actividad lograra en él interés suficiente para dar lo mejor de sí, comunicarse y mostrar sus capacidades.

Categoría III. Sentimientos vivenciados. Esta categoría corresponde a las emociones y sentimientos que las investigadoras y los asistentes de investigación experimentaron durante la ejecución de los talleres. El sentimiento más compartido de manera general fue el de la indefensión experimentada ante la frecuencia de las conductas disruptivas y de agresión de los nińos y las niñas.

De la misma manera, reflexionamos acerca de la falta del sentido de respeto hacia la autoridad, por parte de los niños y las niñas en las actividades del taller. Suponemos que las personas facilitadoras asignadas al taller no fueron concebidas como referentes de su contexto escolar y social. 
Por último, resultó un reto motivar a un pequeño grupo de niños y niñas que emitían respuestas de pasividad o poco interés en el taller.

Categoría IV. Valoración del taller. Esta categoría se refiere a la evaluación que hicieron los niños y las niñas después del taller, como una manera de buscar impresiones y ver su posible impacto en cada participante. En este primer taller las acciones más valoradas fueron brincar, jugar, bailar y pintar una representación de su propia persona (dibujar su silueta en un papel de estraza y colorearla). Destacamos las respuestas más singulares a la pregunta ¿qué fue lo que más te gustó? con las siguientes expresiones: "Me gustó lo que tú me enseñaste", "Me gustó todo", y "No me gustó estar parada". Hubo un grupo que contestó al unísono "Me siento bien".

\section{Taller 2. "Cuerpo que Expresa"}

Objetivo: tener conocimiento de los movimientos naturales y espontáneos propios de cada persona al utilizar el cuerpo, no solo en actos cotidianos, sino en la expresión emocional.

En este segundo taller, a diferencia del primero, donde los niños y las nińas - desde el inicio- mostraron ser capaces de reconocer su esquema corporal, no existía familiaridad con las dinámicas y ejercicios concebidos para lograr el objetivo. De ahí que el taller se asumió como una oportunidad de trabajar la intención a conseguir, expresada en el objetivo anteriormente señalado.

Categoría I. Comportamiento. Para este taller, se mantiene un nivel de participación semejante al ocurrido en el primer taller, es decir, un grupo motivado y participando activamente, otro con un interés leve $y$, por último, aquellos con manifestaciones de conductas disruptivas.

En esta oportunidad notamos que los nińos y las niñas que se involucraban en comportamientos disruptivos y manifestaban una atención dispersa durante el taller, lo hacían siguiendo una necesidad de que quien facilitase el taller se enfocara en su persona, que le viera, le identificara y respondiera a sus preguntas y necesidades.

Nos cuestionamos si esta demanda de atención podría asociarse al escaso rango que ellos y ellas pueden mantener hacia una actividad, es decir, si hubieran recibido suficiente atención por parte de sus seres queridos y maestras, ¿cabría esperar que fueran niños y niñas que se interesan, que se comprometen y hacen propias estas actividades?

Además, se subraya la dificultad que mostraron niños y niñas participantes para seguir la instrucción de algunas actividades, cuyo nivel de complejidad estaba adecuado al rango de edad del grupo. Daba la impresión de que no comprendían lo que se les pedía, por lo cual la facilitadora tenía que estimular con el modelado para lograr una respuesta. Lo acontecido nos lleva a afirmar que la direccionalidad es necesaria para que puedan desarrollar actividades distintas a las realizadas comúnmente en la escuela.

Una situación considerada como relevante fue la resistencia de los niños y las niñas a sentarse en el piso. Quizás este comportamiento se explica, en primer lugar, por la poca limpieza de los pisos de los salones de clases que mostraban las escuelas y, en segundo lugar, la exigencia que hacen los padres al personal docente de que sus hijos regresen a la casa con los uniformes limpios.

Sin embargo, entendemos que esas razones no deberían tener un peso específico como para dificultar la expresividad corporal, que es común en estas edades y niveles de desarrollo en que se encuentra el grupo de estudiantes participantes. Esto nos invita a considerar que, si la maestra no acostumbra a llevar a cabo actividades sobre el suelo, entonces sus alumnos y alumnas tampoco las realizarán.

El taller estaba orientado a hacer surgir las emociones, tanto con ejercicios poco estructurados, 
de manera que la expresividad se diera espontáneamente, como con ejercicios más estructurados. Contrario a lo esperado, a una gran parte de niños y niñas se le dificultó armonizar de manera espontánea las respuestas corporales y las emociones expresadas. Sin embargo, cuando se trataba de ejercicios estructurados como, por ejemplo, "Dígalo como pueda", las respuestas corporales fueron más congruentes con las emociones que indicaba el ejercicio, hecho que alude a la reproducción de las emociones culturalmente construidas.

Un aspecto innovador, producto de la aplicación de estrategias que interpelaran la atención y compromiso de los niños y las niñas con las diferentes actividades del taller, fue la utilización del instrumento musical ukelele. El facilitador que ejecutaba el instrumento lograba tranquilizar a los niños y las niñas con conducta disruptiva, a la vez que suscitaba la atención de los otros nińos y nińas participantes. Cuando el facilitador tocaba el ukelele, el grupo se juntaba a su alrededor y bailaba y lo seguía como en El flautista de Hamelin.

Algunas de las actividades eran amenizadas por parte del equipo facilitador, haciendo uso de panderetas. Resultó llamativa la insistencia de los niños y las niñas en querer tocar y manipular la pandereta, al punto de alterar las actividades y de pelearse entre sí. Se hace evidente la necesidad de que el uso de instrumentos musicales sea parte de las actividades escolares.

Las canciones que incluían gestos corporales (El fideíto y la tetera, por ejemplo) eran ampliamente aceptadas y el grupo las aprendió y las ejecutó con entusiasmo. Esta aceptación se pudiera explicar con el hecho de que este tipo de canciones motoras son grandemente utilizadas en el Nivel Inicial, de manera que el estudiantado las identifica como recursos válidos en la experiencia educativa, por lo que planteamos que estas logran hacerlos sentir en su zona de confort.

En ese sentido, se afirma que la oralidad pueda ser un recurso atractivo y una estrategia que los motiva a responder de manera activa y participativa.
El equipo que facilitó los talleres utilizó el recurso del dibujo para concitar la atención de niños y nińas que manifestaban comportamiento disruptivo. Tal parece que el dibujo retrotrae a las actividades usuales del salón de clases: sentados, utilizando la mesa, con un lápiz en la mano, reconociendo eso como una acción educativa, en vez de los ejercicios creativos y lúdicos que se habían diseñado para el taller. Contraría que el dibujo haya devenido en un medio que limita el desarrollo y la expresión, en vez de ser un detonante de la capacidad creativa, de la expresividad individual, del descubrimiento y la expansión del ser. Pareciera que el dibujo, en esta ocasión, es una anestesia del alma.

Relativo a la conducta disruptiva y de agresión mostrada por miembros del grupo participante, encontramos que eran ejercidas por igual, tanto por nińos como nińas. Esto nos lleva a sugerir que, para este caso, no existe una diferencia de género, tal y como el imaginario invita a considerar para las niñas, de quienes se espera un comportamiento más moderado y suave.

La dificultad de controlar o atenuar las conductas disruptivas puede ser explicada a partir de que, ante todo el grupo, los facilitadores no parecían ser reconocidos como figuras de autoridad. Sin embargo, en el ámbito individual se evidenció que los facilitadores sí alcanzaron cierto control, a través de lograr la participación y cooperación de determinado estudiante.

Las actividades de los talleres concebidas para artifi$c a r^{6}$ la experiencia educativa, al parecer solo fueron un medio de entretenimiento, en vez de resultar una vía propicia para la expresión emocional. Estas dinámicas distaban mucho de las acciones escolares convencionales que, según nuestra visión, poseen una estructura que delimita la creatividad y la

6. Artificar, para las investigadoras, se refiere a llenar de arte las actividades que se lleven a cabo. El arte se concibe como una experiencia transversal del desarrollo humano. 
expresión particular de cada nińo o niña. Podemos interpretar que todos los ejercicios y dinámicas fueron vivenciados como los juegos que hacen en el recreo.

Categoría II. Casos excepcionales. (R) fue un niño que, al inicio del taller, se mostró resistente y poco cooperador y luego, poco a poco, se fue integrando, a partir de que la facilitadora le diera la opción de elegir dónde él quería estar, si en el curso, participando del taller, o fuera de este. (R) decidió quedarse y así se convirtió en un nińo que no solo estuvo presente, sino que sirvió de asistente a la facilitadora.

(V) fue un niño molestoso y poco cooperador, hasta el momento en que el facilitador lo designó como su asistente, entonces, mostró un cambio radical, colaborando con la consecución de las actividades, teniendo iniciativas que complementaban lo que se debía realizar, ayudando a otros niños y niñas sin que se lo pidieran. Al final del taller, $(\mathrm{V})$ realizó un dibujo dedicado de manera especial a cada uno de los y las facilitadoras con los que se relacionó. ${ }^{7}$

(JD) fue el único niño que estaba enfocado en lograr cumplir con los ejercicios de manera completa, evidenciándose un compromiso de su parte hacia las actividades; por ejemplo, en el ejercicio "El autógrafo", que consistía en utilizar el codo como un lápiz para escribir en el aire, hacía diferencias entre las letras mayúsculas y minúsculas.

Categoría III. Sentimientos vivenciados. Un sentimiento experimentado por más de una de las facilitadoras fue el enojo, que llevó a un comportamiento enérgico y de voces fuertes hacia el grupo de estudiantes, con el fin de lograr la atención y participación del grupo completo en las diferentes dinámicas del taller.

7. Se ha omitido el nombre de los niños por razones éticas y que en su lugar se usaran siglas para designar aquellos casos que ilustran comportamientos o situaciones particulares.
Otro de los sentimientos vividos fue el desánimo, a partir de la cuestionante acerca de la viabilidad y efectos del taller sobre el estudiantado participante.

Categoría IV. Valoración del taller. Los niños y las niñas expresaron sentirse felices y contentas. Les gustó jugar mucho. Las actividades preferidas fueron "La Soga", "Enrolla" y "Desenrolla" y "El cuento motor: "La Hoja”. Un niño indicó que lo que más le gustó fue agarrarse de las manos. Los comentarios a destacar fueron: "me hubiera gustado jugar pelota", "me gustó más caminar como tortuga", "lo que más me gustó fue dibujar". Otro niño se sintió tan feliz, como cuando ve "la estufa preparando comida" y el comentario de su maestra fue que "a él le gusta comer mucho". A muchos niños no les gustó tirarse en el piso y ensuciarse.

\section{Taller 3. "Cuerpo que comunica"}

Objetivo: reconocer y valorar el cuerpo y el movimiento como un sistema de comunicación.

En este taller los niños y las niñas reconocieron que, con movimientos de su cuerpo, pueden comunicar, pero no podemos decir que se tienen evidencias de la valoración del cuerpo como sistema de comunicación.

Categoría I. Comportamiento. Este taller se efectuó un miércoles, en vez del día lunes habitual. En dos de las cuatro escuelas se notó una diferencia en el comportamiento del grupo de estudiantes: Este se mostró más interesado, atento y callado, realizando las actividades con ánimo, durante la primera hora del taller.

En una de las escuelas, todo el taller se hizo en una hora, debido al alto y sostenido nivel de atención que demostraron los niños y las niñas. Una primera actividad desarrollada en otra de las escuelas evidenció el cambio de comportamiento de algunos niños frente a su participación en el taller, por ejemplo, al inicio de la primera dinámica, un niño 
solicitó que quería entrar sonriendo al espacio del taller. Interpretamos que con este gesto, el niño se apropiaba del espíritu lúdico del taller. Otro aspecto que se verificó consistió en la consolidación del lazo afectivo entre estudiantes y facilitadores, como fue el caso de una nińa, quien comentó al facilitador que se sentía mal porque él no había estado presente en el taller anterior.

En otra de las escuelas, los niños y las niñas participantes mostraban una cara de satisfacción y alegría. Mientras los primeros hacían sus actividades, un grupo estaba ansioso porque le llegara su turno. Se encontró estudiantes que manifestaban la tendencia a una conducta disruptiva -como pelear-, pero inmediatamente comenzaba la dinámica y el juego, se tranquilizaban para poder participar.

En este tercer encuentro se constató, a diferencia de las dos experiencias previas, una mayor integración de parte del grupo hacia el taller, lo que implica una mejor aceptación de estos espacios novedosos dentro de su jornada diaria. Se mostraron cooperadores y entusiastas.

Categoria II. Caso excepcional. En este tercer taller los grupos de estudiantes se mostraron mucho más cohesionados que en los talleres anteriores, por lo que no se registraron casos individuales que resaltaran con su participación.

Se quiere destacar la alegría que nińos y niñas mostraron cuando veían a las facilitadoras acercarse a su curso para invitarles a participar del taller. Igualmente, cabe resaltar que, en una de las escuelas, el grupo de niños y niñas que permanecía integrado a los talleres, trabajó de manera entusiasta y se mostró divertido.

Categoría III. Sentimientos vivenciados. Para este taller prevaleció la convicción de que los mismos habían tenido y podrían tener un impacto en la expresión de la afectividad y creatividad para beneficio de la experiencia educativa, ya que los facilitadores se sintieron más a gusto, tranquilos e integrados con los grupos de estudiantes que participaron de manera activa en el taller. A manera de ejemplo, citamos la preocupación de un niño, quien inquirió - por una de las facilitadoras- que no estuvo presente en el taller, lo que posiblemente revelaba el establecimiento de un vínculo afectivo.

Categoría IV. Valoración de los niños y las niñas. Algunos participantes expresaron que, después del taller, se sintieron "bien", mientras otros indicaron que lo que más disfrutaron fue colorear y pintar. Se incluye una expresión de un niño al iniciar el taller: "Me sentí emocionado cuando venía para acá", ya que la consideramos como una evaluación de sus experiencias anteriores con los encuentros y nos apunta a considerar que estos tipos de talleres son capaces de ser medios viables para la expresión emocional y el despliegue de la creatividad en el estudiantado.

Los hallazgos del tercer taller, referidos a una mayor integración del grupo de estudiantes participantes, una ejecución entusiasta de las acciones, manifestaciones creativas e involucramiento afectivo, nos llevan a prever que esta tendencia se habría manifestado y aumentado en el taller 4. "Cuerpo que Representa”, que no pudo ser llevado a cabo a causa de una huelga en la comunidad donde se encuentran las escuelas investigadas.

\section{Discusión}

La ejecución de los EPA correspondió al sexto y último objetivo de nuestra investigación: implantar estrategias de intervención lúdicas y artísticas para complementar y apoyar el proceso enseñanza-aprendizaje de los niños y las niñas.

Las estrategias de juego y creativas se organizaron en los EPA, los cuales son un conjunto de cuatro talleres alrededor del tema "cuerpo". El primer taller corresponde a "Cuerpo Vivencial", el segundo taller a "Cuerpo que Expresa", el tercer taller 
a "Cuerpo que Comunica" y el cuarto taller a "Cuerpo que Representa".

Los Encuentros Psico-Afectivos (EPA), se estructuraron de manera secuencial, de forma tal que la complejidad de los ejercicios iba en aumento al pasar de un taller a otro. Iniciando con el cuerpo que vivencia como lo más concreto, luego pasando por el cuerpo expresándose por diferentes medios, sigue la adquisición de una conciencia de la capacidad del cuerpo para comunicar, en este caso sus afectos, sentimientos y capacidad de crear y, por último, el cuerpo en su expresión más abstracta, el cuerpo como medio de representación.

El propósito general de los talleres EPA fue desarrollar actitudes positivas y una expresividad creativa como herramientas para la construcción de una experiencia escolar inclusiva.

Por la investigación estar dirigida a los niños y las niñas de los primeros grados del Nivel Básico, el tema del cuerpo reviste una gran importancia, debido a que es a través de él que se verifican los conocimientos que desarrollan los niños y las niñas acerca de sí y de su entorno.

El primer instrumento de juego que tiene el nińo o la niña es su cuerpo, el cual le permite explorar de manera espontánea, divertida, alegre y libre de presiones externas. Además, en ese ambiente lúdico la capacidad imaginativa se muestra en todo su esplendor, lo que favorece a las expresiones artísticas de toda clase (Piaget, 1986).

Maturana (1992) nos invita a reconocer que ocurre un acoplamiento entre el cuerpo y las relaciones sociales que constituye el espacio psíquico, que como seres humanos- vamos modulando y cambiando a lo largo de toda la vida. Esto quiere decir que no existe psiquis sin cuerpo, al igual que no es posible conocer el cuerpo sin aludir a la psique, por lo tanto, toda experiencia humana, especialmente la del aprendizaje, pasa necesariamente por la dimensión corporal.
Para nosotras, en el cuerpo puede anidar el arte y la afectividad. Es a través del cuerpo que experimentamos la afectividad y es a partir del cuerpo que el arte se justifica. En las edades de los niños y niñas de este estudio, los colores tienen, más que nada, una connotación afectiva. Igualmente, los elementos fundamentales de la música, como el pulso y el ritmo, son aprehendidos a través del cuerpo. Sin embargo, tal y como expone Badilla (2011) a las personas, incluyendo a los niños y las niñas, se les olvida como practicar el arte. Es por ello que los talleres EPA adquieren una gran importancia.

Con respecto al taller 1. "Cuerpo Vivencial", los niños y las niñas participantes fueron capaces de reconocer su esquema corporal global, así como cada parte del mismo, tanto en actividad como en reposo. Sin embargo, se observó que muchos eran rígidos en el movimiento de su cuerpo y se cansaban rápidamente. Si el cuerpo es un repositorio de los sentimientos, hasta qué punto dicha rigidez estará relacionada con el sentimiento de tristeza profunda que se sentía y proyectaba por parte de estos niños y niñas. Este tono emocional presente es incapaz de ser ignorado. Estas explicaciones encuentran un apoyo relativo en los planteamientos de Zubiria (Villegas, 2010) para quien -cada vezes más difícil la manifestación emocional de niños $\mathrm{y}$ adolescentes.

Ahora bien, el grupo de estudiantes de $1^{\circ}$ y $2^{\circ}$ grados fueron quienes disfrutaron más y mejor los ejercicios de este primer taller, sin embargo, parecería que la espontaneidad de los nińos mayores ( $3^{\circ}$ y $4^{\circ}$ ) estuviera menguada.

Las conductas disruptivas y de agresión encontradas resultaron importantes, y más debido a que esos comportamientos parecían cotidianos, ya que se manifestaban frente a las docentes y ellas no exhibían ninguna sorpresa. Entendemos que esta conducta disruptiva habla de que los ámbitos de socialización de estos estudiantes están caracterizados por la agresividad. 
Para el caso de las docentes, podemos decir que encontramos un tipo de rechazo pasivo en su actitud poco receptiva frente a los talleres y su involucramiento. Es posible sugerir que, al igual que en los niños y las niñas, para ellas estos talleres no representan un accionar de la experiencia educativa, concebida, como todavía ocurre, a partir de una formalidad y estructura que no asume lo lúdico como forma de aprendizaje. Y, quizás por esto, ellas no sentían que estos encuentros podían interpelarlas a ser partícipes y encontrar (ellas mismas y, luego, los niños y las nińas) una experiencia significativa tanto como una manera novedosa de aprender, como un espacio para la afectividad.

A pesar de las conductas disruptivas, los niños y las niñas permanecían en el taller, no querían irse, aún se mantuvieran con este comportamiento, lo que nos hace sostener la hipótesis de que algo de lo que se realizaba allí tocaba su afectividad, como para desear estar en el taller.

Para el caso de los niños y las niñas con poca participación, el estar allí se pudiera interpretar como una necesidad de recibir atención por parte de los adultos, quizás por la existencia de carencias afectivas. Los talleres EPA representarían en el niño o la niña que minimamente hay un valor hacia mi persona, cuando se me toma en cuenta.

Si partimos de que los niños y las nińas provienen de un contexto primario con vacíos afectivos, entonces, a mi que tú me atiendas, bajo cualquier circunstancia, es porque me tienes presente; lo que no quiero es sentirme invisible. $\mathrm{Y}$ es porque estos niños y niñas vienen de una invisibilidad social.

En este primer taller, donde hubo que motivar de manera sostenida a los nińos y las niñas para que participaran, se observó limitaciones en la oportunidad de expresarse y ser en su diferencia. Esto pudiera explicarse debido al continuo reforzamiento de la tendencia homogeneizante en la experiencia escolar: sentado, callado y con un libro o cuaderno en la mano. O, podemos decir, que los niños y las niñas se defienden de lo que no conocen.

Para el taller 2. "Cuerpo que Expresa", a diferencia del primer taller, las dinámicas y ejercicios ejecutados no resultaron comunes para los niños y las nińas, ya que no se les hizo fácil ejecutarlas de manera precisa. Los movimientos realizados para la expresión de actos de la cotidianidad, así como para la manifestación de sentimientos, fueron poco naturales y espontáneos.

Fue notoria la atención dispersa que mostraban los niños y las nińas, la cual interpretamos que se vincula con un rango leve de atención para mantener una actividad de manera sostenida. Nos atrevemos a indicar que si hubieran recibido suficiente atención y trato cálido por parte de sus padres y maestras o maestros, entonces fuera posible ser testigo de infantes que se interesan, que se comprometen y hacen suyas cualquier actividad, ejercicio o dinámica novedosa que se le presentase.

La dificultad para seguir inmediatamente las instrucciones y depender del modelado de la maestra o facilitador alude a una falta o pérdida de la espontaneidad que no debía encontrarse en estas primeras etapas del desarrollo. Esto se explica por la inhibición provocada artificialmente por una escuela con una pedagogía vertical y directiva. Para apoyar esta afirmación señalamos el gran impedimento por parte de los niños y las niñas para mostrar con su cuerpo sentimientos de manera espontánea $y$, en cambio, la facilidad exhibida cuando se trataba de reproducir aquellas emociones culturalmente construidas.

Relacionado con lo descrito anteriormente, se encuentra el disfrute de las canciones, sobre todo las de tipo motoras, las cuales se aprendieron y ejecutaron con entusiasmo. Esto se justifica, ya que estas hacen que los niños y las niñas se remonten a la experiencia agradable de la educación inicial, además de que son identificadas como válidas en la 
experiencia educativa. Es decir, los niños y niñas se encontraban en un terreno conocido.

La repetición sucesiva de canciones limita las expresiones espontáneas, esperadas para los nińos y las niñas en esta época de sus vidas. A su vez, restringe las exploraciones propias al mundo circundante y el juego con la imaginación que implica experiencias placenteras, ampliar las relaciones sociales, la construcción de saberes propios, el manejo de conflictos y la oportunidad de revelar su mundo interior, por lo tanto, la expresión de la afectividad se ve muy reducida.

En la consecución de este segundo taller, fue imprescindible la utilización de la técnica del dibujo libre, la cual no fue considerada como una actividad diseñada para estos talleres, sino que surgió en su desarrollo, como una respuesta de intervención que buscaba aminorar la conducta disruptiva. Entregado el papel y los colores, el grupo modificaba su actitud, y, hacer el dibujo, le llevaba a sentarse en las mesas, tomar los colores y dibujar en ese estilo mecanizado de la experiencia escolar. Al observar sus creaciones, estas no indicaban experiencias particulares de sus vivencias ni de su mundo interior, sino que se representaban los elementos repetitivos de su experiencia inmediata en la escuela: la bandera, las plantas, la misma escuela, o calcar figuras de los libros.

De la misma manera como ocurrió en la experiencia del primer taller, hubo manifestación de comportamientos agresivos. Lo que se quiere destacar, en esta oportunidad, es el hecho de que la agresión era ejercida de manera equitativa, tanto por niños como por niñas, lo que confirma lo referido en acápites anteriores, acerca del impacto desempeñado por esos contextos socializadores agresivos.

La estrategia artística más innovadora de este taller estuvo alrededor de la música, introducida por un instrumento nada común en la escuela, el ukelele, así como los panderos, instrumentos más conocidos y familiares. Las actividades con estos instrumentos, y los instrumentos en sí, despertaron un gran interés en muchos niños y niñas, no solo al escucharlos, sino que deseaban manipularlos y producir sus sonidos. Estas manifestaciones de interés nos recuerdan lo postulado por Abad (2009) acerca del arte como ejercicio educativo que propicia la construcción e incorporación de la cultura.

Las manifestaciones del estudiantado sugieren que, si se integrasen más actividades con la música y la manipulación de instrumentos u otros objetos atractivos, además de más espacios para la exploración en sí, la experiencia educativa sería más auténtica. Como se confirma en esta investigación, donde las inteligencias cinético-corporal y musical son expresiones de las disposiciones de estos niños y niñas, entonces acciones educativas desde la música, serían diversas, inclusivas y contextualizadas. Esto afianza lo señalado por Jiménez (2010) acerca de que la educación artística y la educación a través del arte, hacen posible contrarrestar, no solo el analfabetismo tradicional, sino nuevas formas de exclusión social, como es el analfabetismo estético.

En este segundo taller, si bien los facilitadores (frente al grupo general) no éramos identificados como figuras de autoridad, en la experiencia individual con algunos niños y niñas sí se logró un vínculo significativo. De haberse mantenido la entrega de talleres por más tiempo, se habría logrado desarrollar la suficiente aceptación para poder ser actores con influencia en el grupo.

Para el Taller 3. "Cuerpo que Representa”, los niños y las nińas lograron, parcialmente, comunicarse con su cuerpo, sin embargo esto se realizó sin una total conciencia de la capacidad del cuerpo de representar sentimientos. Esto quiere decir, que ellos y ellas mostraron atisbos de su esfera emocional y vida interior, al realizar las actividades del taller, pero con dificultades para la expresividad espontánea de sus sentimientos. Este hallazgo se confirma de manera parcial por lo planteado por Pozzoli (2007) que explica que el arte es una vía de reconocimiento y 
manifestación de la vida interior, por lo cual tiene un poder reconstructor del ser profundo.

A diferencia de los talleres anteriores, en esta oportunidad el grupo de estudiantes estaba centrado, logrando una atención de manera sostenida en la realización de las actividades, por lo menos durante una hora completa o algo más.

Los niños y las niñas comunicaron y mostraron emociones de alta valoración de los talleres, por lo que las facilitadoras y facilitadores percibieron que los talleres comenzaban a ejercer el sentido propuesto en ellos. A pesar de que hubo conductas disruptivas, estas eran dejadas de lado para integrarse a las actividades del taller. Los niños y las nińas se mostraron cooperadores y entusiastas. Sin embargo, esto fue evidente en el grupo que era constante en la participación y no así en el grupo ampliado.

\section{Conclusiones}

Los Encuentros Psico-Afectivos (EPA) han mostrado que los diferentes ejercicios y dinámicas relativas al cuerpo pueden tener un impacto en la expresión de sentimientos y el desarrollo de la creatividad en la experiencia educativa, propósito para el cual fueron creados. Sin embargo, desplegar la creatividad va a requerir de un proceso más largo del iniciado con estos talleres EPA, que ofrecen una oportunidad para la manifestación afectiva.

Si cada estudiante es capaz, cada vez más, de poder distinguir las diferentes emociones que experimenta, es posible -por medio a la creatividad y el arte-, encontrar caminos alternos a las conductas disruptivas y de agresión, las cuales son producidas, entre otros factores, por un manejo inadecuado de las emociones que las caracterizan.

Podemos decir que los talleres EPA, al incorporar lo artístico como puente hacia la expresión afectiva, si son utilizados en la experiencia educativa, posibilitarán el desarrollo de las potencialidades y la aceptación de la diversidad de todos los actores involucrados.

Deseamos señalar que, de haberse efectuado el cuarto y último taller del ciclo programado, "Cuerpo que Representa", los aspectos positivos alcanzados por el estudiantado con el tercer taller, tanto en la afectividad como en la manifestación creativa, se habrían consolidado en este cuarto encuentro. Para asegurar esto, nos basamos, en primer lugar, en la aceptación percibida en los niños y las niñas de estos espacios novedosos como parte de la experiencia educativa y, en segundo lugar, debido a la finalidad concebida para este cuarto taller, que consistía en representar vivencias, emociones y situaciones, por medio de la imaginación, lo perceptual y el conocimiento propio de las posibilidades del cuerpo y su movimiento como un lenguaje particular, propiciando que cada participante sea autor y actor de su mundo.

\section{Bibliografía}

Abad, J. (2009). Usos y funciones de las artes en la educación y el desarrollo humano. En L. Jiménez, I. Aguirre, \& L. Pimentel (Coods.). Educación Artística Cultura y Ciudadanía (1-183). España: OEI. Recuperado de: http://www.oei.es/metas2021/EDART2.pdf

Badilla, F. (2011). Arte Terapia: Una Manera de Fortalecer la Autoestima. (Tesis inédita de Maestría). Universidad de Chile. Santiago, Chile. Recuperado de: http://www.tesis.uchile.cl/tesis/uchile/2011/ ar-badilla_f/pdfAmont/ar-badilla_f.pdf

Gardner, H. (1997). La mente no escolarizada. Cómo piensan los niños y cómo deberían enseñar las escuelas. México-España: Biblioteca del Normalista.

Gardner, H. (1993). Frames of Mind. The Theory of Multiple Intelligences. Gran Bretaña: Fontana Press. 
Hernández M., R. \& Pacheco, B. (2012). Vivir Feliz como Propuesta para un Quehacer Docente Imaginativo e Inclusivo. República Dominicana: OEI y MINERD.

Hernández M., R. \& Andujar, C. (1999) Valoración del desarrollo socioafectivo. Instrumento, resultados y conclusiones. República Dominicana: Secretaría de Estado de Educación.

Hernández, R. (2012). Ambientes afectivos y efectivos de aprendizaje. Ponencia realizada en el Foro de Innovación en la Docencia. Xalapa, Veracruz: Facultad de Pedagogía Xalapa. Universidad Veracruzana. Recuperado de: http://www.uv.mx/ personal/rubhernandez/files/2012/02/Amb_afectivos_efectivos.pdf

Jiménez, L. (2010). Arte, cultura y ciudadanía: hacia la construcción de valores. En B. Toro \& A. Tallone (Eds.), Educación, valores y ciudadanía. Metas Educativas 2021 (203-214). Espańa: OEI \& Fundación SM.

Maturana, R. H. (1992). El Sentido de lo Humano. Chile: Hachette y Ediciones Pedagógicas Chilenas.

Maturana, H. (1990). Emociones y Lenguaje en Educación y Politica. Chile: Hachette/CED.

Piaget, J. (1986). Seis Estudios de Psicología. Barcelona: Barral Editores.

Pozzoli, M. T. (2007). Espiritualidad, Arte y Belleza: Espacios del universo para el desarrollo humano desde el pensamiento complejo. Polis, Revista de la Universidad Bolivariana, 5 (17) 1-13. Recuperado de http://www.redalyc.org/articulo. oa? id $=30501708$

Restrepo, G. (2009). Contextos afectivos y cognitivos en los procesos de aprendizaje. Revista Complutense de Educación, 20(1) 195-204. Recuperado de: http://revistas.ucm.es/index.php/ RCED/article/view/RCED0909120195A/15425
Rodríguez, G. (2010). Sentimientos y actitudes en la escuela. B. Toro \& A. Tallone (Coords.), Educación, Valores y Ciudadanía (231-247). Madrid: Organización de Estados Iberoamericanos para la Educación, la Ciencia y la Cultura.

Santiago, E. (2009). Música como Estrategia Educativa en el Proceso Enseñanza Aprendizaje para el Aprovechamiento de los Estudiantes del Nivel Elemental en la Región Educativa de Bayamón. (Tesis inédita de Maestría).Universidad Metropolitana Río Piedras, Puerto Rico. Recuperado de: http:// www.suagm.edu/umet/biblioteca/UMTESIS/ Tesis_Educacion/Adm_Sup_Educativa/ ESantiagoSilva.062309.pdf

Tirado, V. (2008). El proceso de Enseñanza Aprendizaje a través de las Artes Plásticas en la Educación Preescolar. (Tesis inédita de grado). Universidad Pedagógica Nacional, Sinaloa, México: Recuperado de: http://biblioteca.ajusco.upn.mx/ pdf/26368.pdf

Vásquez, J. (2011). El valor del dibujo para la educación infantil. Recuperado de http://www.eduinnova.es/monografias2011/ene2011/dibujo.pdf

Villamán, M. (2003). Reinventar la Escuela: algunas posibles provocaciones. En Centro Poveda (Eds.), Reinventar la Escuela: ¿Qué Opciones? Reflexiones sobre el futuro de la educación dominicana (67-106). República Dominicana: UNESCO en Santo Domingo. Recuperado de http://www. minerd.gob.do/idec/Docs5/Reinventar\%20la\%20 escuela.pdf

Villanueva, E. (2013). Danza y Educación. En Ministerio de Educación de República Dominicana (Eds.), Propuestas ante los cambios que requiere la actualización curricular. Naturaleza, contenidos y competencias (87). VIII Foro Nacional Educación Artística. Santo Domingo.

Villegas, C. (2010, septiembre). La afectividad como el eje central del encuentro educativo. 
Ponencia presentada en Congreso Iberoamericano de Educación Metas Educativas 2021. Buenos Aires, Argentina: Organización de los Estados Iberoamericanos para la Educación, la Ciencia y la Cultura. Recuperado de http://www.chubut.edu. ar/descargas/secundaria/congreso/METAS2021/ R0734b_Poster_Villegas.pdf

\section{Datos de filiación}

Patricia Liranzo Soto. Es psicóloga clínica, profesora e investigadora del Área de Ciencias Sociales y Humanidades del Instituto Tecnológico de Santo Domingo (INTEC). Posee una maestría en el área de Psicología Clínica por la Universidad Autónoma de Santo Domingo; licenciatura en Psicología; curso Experto en Peritaje Psicológico e Intervención Judicial; curso en Diagnóstico y Rehabilitación Neuropsicológica en Neurología Conductual; curso en Evaluación e Intervención Psicofisiológica en Medicina Conductual. Entre sus publicaciones están: Las diosas sometidas: autoconcepto en mujeres de grupos vulnerables. Encuentros afectivo-participativos y sus efectos en el self (2013); Apego y autoestima estudiantes femeninas en Psicologia (2012); El proceso de descentralización escolar y sus condiciones de posibilidad (2006). Correo electrónico: patricia.liranzo@ intec.edu.do

Rocío Hernández Mella. Profesora-investigadora del Área de Ciencias Sociales y Humanidades del Instituto Tecnológico de Santo Domingo, INTEC. Doctora en Psicología Social; maestría en Planificación y Administración de la Educación; especialización en Psicología Educativa y licenciatura en Psicología. Entre sus publicaciones recientes están: Las diosas sometidas: Autoconcepto en mujeres de grupos vulnerables. Encuentros afectivo-participativos y sus efectos en el self (junto a Patricia Liranzo, 2014), Vivir feliz como propuesta para un quehacer docente imaginativo e inclusivo (junto a Berenice Pacheco, 2012); El arte salva (capítulo, 2012). Líneas de investigación: Psicología; calidad y procesos educativos. Correo electrónico: rocio.hernandez@intec.edu.do

Aurora Andreína Jiménez Soto. Es egresada de la carrera de Psicología de Instituto Tecnológico de Santo Domingo (INTEC), maestría en Gerencia Educativa en UNIBE; especialidad en Educación Artística, Cultura y Ciudadanía. Actualmente se desempeña como Técnico Docente Nacional del Área de Educación Artística de la Dirección General de Currículo del Ministerio de Educación; profesora de INTEC. Correo electrónico: aajsoto@ gmail.com

BerenicePacheco-Salazar. EsdoctoraenEducación por la Universidad de Sevilla. Es licenciada en psicología con maestría en Género, Investigación y Desarrollo. Docente de la Universidad INTEC. Líneas de investigación: la violencia escolar; género y violencia, atención a la diversidad, y convivencia y mejora de las instituciones educativas. Correo electrónico: bereniceps@gmail.com 